\title{
Radiative and Convective Driving of Tropical High Clouds
}

\author{
Terence L. Kubar, Dennis L. Hartmann, and Robert Wood \\ Department of Atmospheric Sciences, University of Washington, Seattle, Washington
}

(Manuscript received 8 August 2006, in final form 2 April 2007)

\begin{abstract}
Using satellite cloud data from the Aqua Moderate Resolution Imaging Spectroradiometer (MODIS) and collocated precipitation rates from the Advanced Microwave Scanning Radiometer (AMSR), it is shown that rain rate is closely related to the amount of very thick high cloud, which is a better proxy for precipitation than outgoing longwave radiation (OLR). It is also shown that thin high cloud, which has a positive net radiative effect on the top-of-atmosphere (TOA) energy balance, is nearly twice as abundant in the west Pacific compared to the east Pacific. For a given rain rate, anvil cloud is also more abundant in the west Pacific. The ensemble of all high clouds in the east Pacific induces considerably more TOA radiative cooling compared to the west Pacific, primarily because of more high, thin cloud in the west Pacific. High clouds are also systematically colder in the west Pacific by about $5 \mathrm{~K}$.

The authors examine whether the anvil cloud temperature is better predicted by low-level equivalent potential temperature $\left(\Theta_{\mathrm{E}}\right)$, or by the peak in upper-level convergence associated with radiative cooling in clear skies. The temperature in the upper troposphere where $\Theta_{\mathrm{E}}$ is the same as that at the lifting condensation level (LCL) seems to influence the temperatures of the coldest, thickest clouds, but has no simple relation to anvil cloud. It is shown instead that a linear relationship exists between the median anvil cloud-top temperature and the temperature at the peak in clear-sky convergence. The radiatively driven clear-sky convergence profiles are thus consistent with the warmer anvil clouds in the EP versus the WP.
\end{abstract}

\section{Introduction}

Upper-tropospheric clouds associated with tropical convection have large shortwave (SW) and longwave (LW) cloud radiative forcing (CRF). Clouds reflect SW radiation, which cools the planet, and the size of the effect is determined primarily by cloud optical depth. Clouds trap LW radiation, which tends to warm the climate, and primarily depends on cloud-top temperature, except for relatively thin clouds (visible optical depth $\tau \leq 4$ ), in which the LW effect increases with optical depth as well. The ensemble of convective clouds is such that the SW and LW effects come fairly close to canceling (Harrison et al. 1990). Using International Satellite Cloud Climatology Project (ISCCP) data, Hartmann et al. (2001) show that in an area of the west Pacific, the net CRF is on the order of about -10 $\mathrm{W} \mathrm{m}^{-2}$, and a considerably larger negative net CRF in a portion of the east Pacific ITCZ region of about

Corresponding author address: Terence L. Kubar, Dept. of Atmospheric Sciences, University of Washington, Box 351640, Seattle, WA 98195-1640.

E-mail: tkubar@atmos.washington.edu

DOI. 10.1175/2007JCLI1628.1

(C) 2007 American Meteorological Society
$-45 \mathrm{~W} \mathrm{~m} \mathrm{~m}^{-2}$ is observed. It is suggested that this is because clouds are warmer and optically thicker in the east Pacific. Berg et al. (2002) and Schumacher and Houze (2003) have also studied structural differences, and infer the existence of shallower rainfall systems with more stratiform precipitation in the east Pacific.

We construct temperature-optical depth $(\mathrm{T}-\tau)$ histograms to better understand differences in high cloud properties in the west Pacific (WP; $5^{\circ}-15^{\circ} \mathrm{N}, 120^{\circ}-$ $\left.160^{\circ} \mathrm{E}\right)$, central Pacific $\left(\mathrm{CP} ; 5^{\circ}-15^{\circ} \mathrm{N}, 160^{\circ} \mathrm{E}-160^{\circ} \mathrm{W}\right)$, and east Pacific (EP; $\left.5^{\circ}-15^{\circ} \mathrm{N}, 150^{\circ}-100^{\circ} \mathrm{W}\right)$. These histograms are then used in conjunction with a radiation model in order to quantify radiative effects of convection across the ITCZ, in a similar spirit as Hartmann et al. (2001), but with much higher vertical resolution afforded by Moderate Resolution Imaging Spectroradiometer (MODIS) data. We also are interested in the driving mechanisms behind the structure of these histograms, and thus we composite high cloud fraction with rain rate. Composites by rain rate normalize convective intensity, so that we can then examine more subtle effects on convection, such as those from SST, SST gradients, and ITCZ structure across the North Pacific. 
We also wish to address the claim that cloud systems are shallower in the EP, but in doing so we ask how high tropical clouds get and what controls their detrainment level. Reed and Recker (1971) analyzed satellite data composites that revealed a peak in stratiform anvil and thin cloud around $175 \mathrm{hPa}$, which corresponds to approximately $13 \mathrm{~km}$. They also made upper-level divergence calculations, which suggested a peak at around the same level. Other studies have also suggested convective detrainment well below the tropopause. Folkins et al. $(1999,2000)$ suggest that convective detrainment occurs below $14 \mathrm{~km}$, based on $\mathrm{O}_{3}$ concentrations that begin increasing toward stratospheric concentrations at this level.

So, what determines the top of the tropical convective layer, and why is this top apparently well below the tropopause? The "Hot Tower" concept of Riehl and Malkus (1958) and Riehl and Simpson (1979) assumes that convection occurs such that saturated ascending parcels are undiluted, and become negatively buoyant around $150 \mathrm{hPa}$, making this a cap for convection, which again is below the tropopause. Folkins et al. $(1999,2000)$ also state that undiluted parcels become negatively buoyant once they reach the level in the upper atmosphere in which environmental $\Theta_{\mathrm{E}}$ is the same as $\Theta_{\mathrm{E}}$ at the LCL. We refer to these ideas as the "PUSH" mechanism, as high clouds are convectively driven by energy present in low-level air. An alternative perspective, which we refer to as the "PULL" mechanism, is that clear-sky radiatively driven upperlevel convergence determines the level at which detrained cloud is maximum. Clear-sky radiative cooling drops off quickly in the upper troposphere where water vapor levels rapidly decrease, since saturation vapor pressure is dependent only on absolute temperature, per the Clausius-Clapeyron relationship. Hartmann and Larson (2002) have argued that the PULL mechanism implies an essentially fixed anvil cloud temperature.

To evaluate the PULL mechanism, we use a radiative transfer model to calculate clear-sky cooling rates and the corresponding upper-level convergence. We then examine to what extent anvil outflow occurs at this level, as evidenced by cloud temperatures measured by MODIS. We will quantify the relationship between clear-sky convergence and cloud temperature. The goal is to characterize the mechanisms that determine the altitude of convective clouds in the ITCZ.

\section{Data for cloud $T-\tau$ histograms}

We use data from Aqua MODIS, which is a sunsynchronous satellite with local daytime overpass time at the equator of 1330 local time. The MODIS cloud products include cloud mask (which assesses the probability that there is a cloud in a given pixel), cloud-top properties (i.e., temperature, pressure), cloud optical depth, and cloud phase. The horizontal spatial resolution of five $\mathrm{km}$ of the Joint Level-2 MODIS dataset is higher than other remote sensing instruments of similar spatial coverage (Platnick et al. 2003). The nature of a sun-synchronous satellite, however, does preclude the observation of the diurnal cycle.

Cloud optical depth retrievals are based on solar reflectance. Clouds are assumed to be homogeneous, and ice and liquid cloud lookup tables are used (King et al. 1997). A nonabsorbing wavelength band $(0.86 \mu \mathrm{m})$ is used to reduce the effect of particle size (King et al. 1997).

To estimate cloud-top temperature, the Joint Level-2 dataset is used, which has the same horizontal resolution for cloud-top temperature and cloud fraction (5 $\mathrm{km})$ as the full Level-2 data. Though the Joint dataset has lower resolution for $\tau(5 \mathrm{~km}$ versus $1 \mathrm{~km})$ than the standard Level-2 swath product, its smaller data volume is an advantage. For clouds above $700 \mathrm{hPa}$, a $\mathrm{CO}_{2}{ }^{-}$ slicing method is used (Platnick et al. 2003). This method utilizes the partial absorption in each of two different MODIS infrared bands. Within the $15-\mu \mathrm{m}$ $\mathrm{CO}_{2}$ absorption region, the ratio pairs used by MODIS are 14.2/13.9 $\mu \mathrm{m}, 13.9 / 13.6 \mu \mathrm{m}, 13.6 / 13.3 \mu \mathrm{m}, 13.9 / 13.3$ $\mu \mathrm{m}$, and 13.3/11 $\mu \mathrm{m}$ (Platnick et al. 2003). Each MODIS band senses a different atmospheric layer. Upward infrared emission is measured in each of the different bands, and cloud pressure is then determined. With use of the National Center of Environmental Prediction (NCEP) reanalysis tables, cloud-top temperature is then estimated. In the lower troposphere (below $700 \mathrm{hPa}$ ), the $\mathrm{CO}_{2}$-slicing method is less effective, and is replaced with band temperatures within the $11-\mu \mathrm{m}$ atmospheric window. One major advantage of $\mathrm{CO}_{2}$ slicing is that it is relatively insensitive to emissivity, so that the temperature of thin clouds can be sensed more accurately compared to estimates based on brightness temperatures alone (Platnick et al. 2003).

Because our interest is in tropical oceanic convection, only areas over the open ocean are considered. Also, because we are interested in both thermal and optical properties, only daytime data are used. Data influenced by sun glint are not used.

Instantaneous satellite retrievals are aggregated into 3 -day averages and $1^{\circ}$ latitude $\times 1^{\circ}$ longitude regions. This averages together individual convective events occurring on short time (less than 1 day) and small spatial scales (less than about $100 \mathrm{~km}$ ). These temporal and 


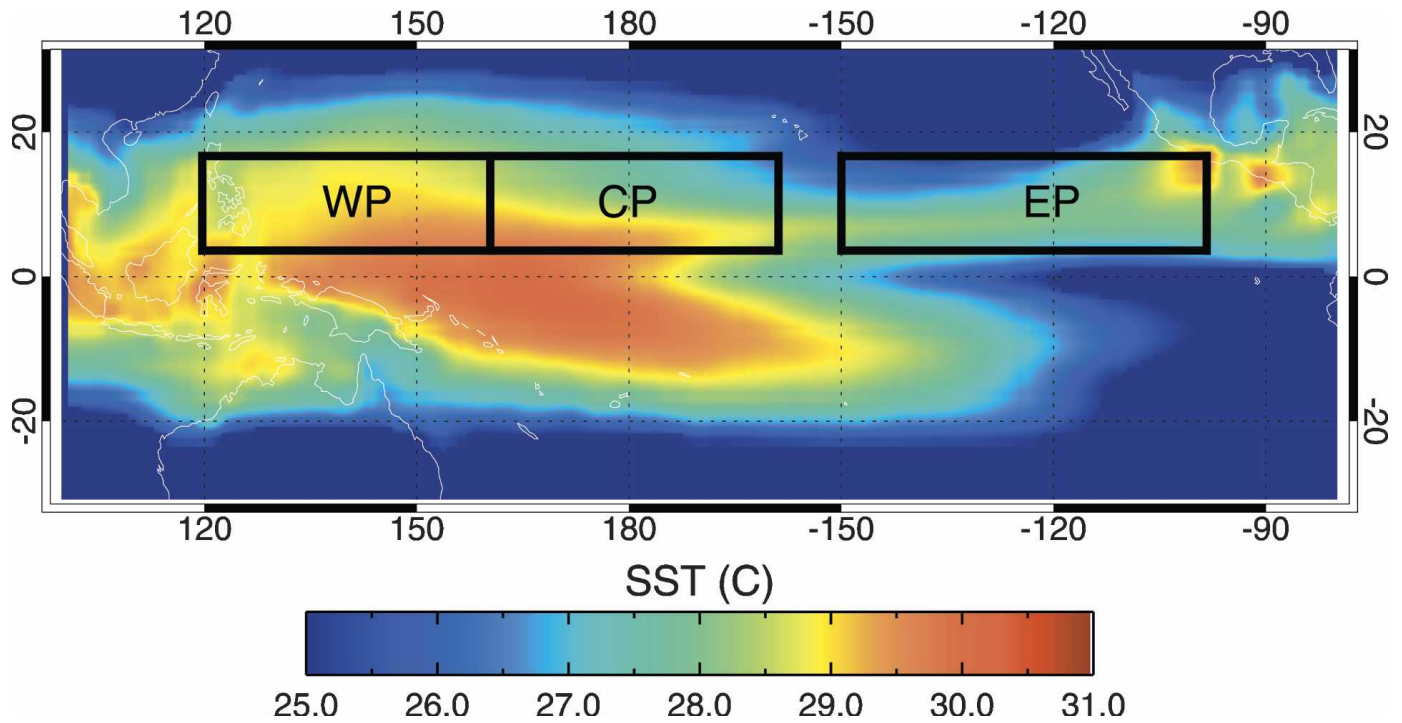

FIG. 1. Map of composite SSTs over the tropical Pacific for September 2003-August 2005, indicating the three regions selected for study.

spatial scales are small enough to capture variability in convection. (We do in fact test the sensitivity of different temporal and space scales, and determine that it is quite low.)

We use weekly SST data from the Climate Diagnostics Center, which contain National Oceanic and Atmospheric Administration (NOAA) Optimum Interpolation (OI) SST version-2 data. These data are global, have $1^{\circ} \times 1^{\circ}$ resolution, and are derived from a combination of in situ and satellite measurements (Reynolds et al. 2002). These data are interpolated onto the same temporal scale as the MODIS data.

Daily rain-rate data on a grid of $0.25^{\circ} \times 0.25^{\circ}$ comes from the Advanced Microwave Scanning Radiometer (AMSR), which is also aboard the Aqua satellite. The obvious advantage of this is the collocation (in space and time) with MODIS. Its microwave frequencies can detect larger raindrops through smaller cloud particles, and it becomes saturated for precipitation rates of 25 $\mathrm{mm} \mathrm{h}^{-1}$. We use the version-5 rain rates, which have an improved rain algorithm in which freezing levels have been revised, lowering calculated rain rates in the Tropics compared to older versions (Remote Sensing Systems 2006). Like the SST data and MODIS data, rain rate data are aggregated into 3-day averages for compositing purposes with MODIS cloud data.

To further ensure the statistical robustness of the MODIS data, we use only aggregated 3-day $1^{\circ}$ latitude $\times 1^{\circ}$ longitude data that contain at least $200 \operatorname{good} 5-\mathrm{km}$ boxes. These include boxes that are well removed from land, free of sun glint, and have a determined cloud mask (land/water, sun glint, and cloud mask quality flags are used). During a 3-day period, a maximum of 1200 good boxes are possible, since $1^{\circ}$ of latitude/ longitude near the equator is about $100 \mathrm{~km}$, and the horizontal resolution of Joint Level-2 MODIS is $5 \mathrm{~km}$. The threshold of 200 good boxes to define data that are good that meet the above criteria perhaps is somewhat arbitrary, but does filter out 3-day periods in which relatively few good boxes exist. To examine the sensitivity to the given temporal and spatial resolution, calculations are also performed with 1-day periods, and the results are largely unchanged (figures not presented in this report). The same is also true when $5^{\circ}$ latitude $\times$ $5^{\circ}$ longitude boxes are chosen. Thus, the results are not sensitive to the spatial or temporal resolution.

To understand both qualitatively and quantitatively the structure of clouds across the ITCZ, cloud fraction histograms, categorized by temperature (ordinate) and optical depth (abscissa) are constructed, which we will refer to as $T-\tau$ histograms. The three regions, namely the WP, CP, and EP, have different SST distributions, with the WP representing the large warm pool region, the $\mathrm{CP}$ a transition zone of sorts, and the EP a narrow ITCZ, with strong SST gradients on its edges. A composite SST map from September 2003 through August 2005 is given in Fig. 1. It should be noted that the median SST in the WP during this period is $28.9^{\circ} \mathrm{C}, 28.5^{\circ} \mathrm{C}$, in the $\mathrm{CP}$, and $27.9^{\circ} \mathrm{C}$ in the EP. For the $T-\tau$ histograms, 26 temperature bins of $5^{\circ}$ and 10 optical depth bins are used, the latter of which follows a nearly logarithmic scale with the following bins: $0-0.125,0.125-$ $0.25,0.25-0.5,0.5-1.0,1.0-2.0,2.0-4.0,4.0-8.0,8.0-16.0$, 16.0-32.0, 32.0-64.0. We have a total of 260 possible 
cloud bins, which provides much greater resolution than the 42 ISCCP pressure/optical depth bins. However, it is primarily in the vertical that MODIS $T-\tau$ histograms are superior to ISCCP. For example, in the upper troposphere, the ISCCP pressure bins are 440 to $310 \mathrm{hPa}, 310$ to $180 \mathrm{hPa}$, and 180 to $30 \mathrm{hPa}$. These correspond to approximate temperature ranges (based on GPS data) of 260-240 K, 240-215 K, and 215-193 K (at $100 \mathrm{hPa}$ ), which are coarse compared to the 5 -K bins used here. These histograms are discussed in a later section.

\section{Radiative transfer model $/ T-\tau$ histogram methodology}

We employ the same radiation model as used by Hartmann et al. (2001), namely the Fu and Liou (1993) delta-four-stream, k-distribution scheme. The purpose of a radiative transfer model is twofold: we calculate radiative energy budgets for each of our cloud categories, and we also use clear-sky heating rates (to be discussed later) for calculation of clear-sky convergence profiles. We focus on the former in this section.

For each of the aforementioned cloud types, cloud radiative forcing is calculated, assuming $100 \%$ cloud cover in each bin. These are computed every hour for the centers of the WP, CP, and EP, with zenith angles corresponding to day 90 of the year. Ice water content (IWC) is calculated by the relationship

$$
\mathrm{IWC}=\frac{2}{3} \frac{r_{\text {ice }} \tau_{\text {ice }}}{\Delta z},
$$

where $r_{\text {ice }}$ is the effective radius of ice, $\tau_{\text {ice }}$ is the optical depth, and $\Delta z$ the geometric thickness of the cloud. An analogous relation is used for liquid water content (LWC); cloud is assumed to be all ice at temperatures below $263 \mathrm{~K}$. No mixed clouds are included, but this is not seen as a major problem, since the emphasis of this study is that of tropical high cloud. Also, as in Hartmann et al. (2001), $r_{\text {ice }}$ is assumed to be $30 \mu \mathrm{m}$, and $r_{\text {liquid }} 10 \mu \mathrm{m}$. According to Korolev et al. (2001), the dependence of particle size on temperature is quite weak. Thus, without further detailed information about an exact dependence of particle size on temperature, selecting one value for ice and one for liquid seems to be a good assumption. A more quantitative analysis of this assumption is examined in a later section. Geometric cloud thickness $\Delta z$ is based on climatology from Liou (1992), which contains nine thickness categories, depending on cloud height and optical depth. Concentrations of $\mathrm{CO}_{2}, \mathrm{CH}_{4}$, and $\mathrm{N}_{2} \mathrm{O}$ are assumed to be 330 , 1.6 , and 0.28 ppmv, respectively, and the surface albedo is 0.05 (a reasonable value for the ocean). (Calculations were also made using more current greenhouse gas values, and there was very little sensitivity of radiative calculations to greenhouse gas concentrations.)

In Fig. 2, contours of shortwave, longwave, and net top-of-atmosphere (TOA) radiation are shown in $T-\tau$ coordinates. Optical depth matters more for SW cloud forcing, and cloud-top temperature has only a marginal effect, so that clouds have a much stronger SW cooling effect as their optical thickness increases. On the other hand, cloud-top temperature and cloud optical depth are both important for LW cloud forcing for optically thin clouds ( $\tau<4$ or so). For such clouds, as optical thickness increases, so does the LW warming effect. For all clouds, the LW effect increases with decreasing cloud-top temperature, and for clouds with an optical thickness greater than four, only cloud-top temperature matters. The net CRF is positive for thin cloud colder than $260 \mathrm{~K}$, and reaches a peak (of $+94.3 \mathrm{~W} \mathrm{~m}^{-2}$ ) for very cold clouds at around $\tau=1$, and then decreases with increasing $\tau$. It becomes negative for larger optical depths, but becomes negative at lower optical depths for warmer clouds. We choose our high cloud to include clouds colder than $245 \mathrm{~K}$, as this represents a temperature at which high cloud amount is well separated from other cloud modes (a relative minimum in cloud amount appears at approximately this temperature). Low, thick clouds have a negative forcing with a value of about $-216 \mathrm{~W} \mathrm{~m}^{-2}$.

\section{Cloud fraction histograms and radiative flux histograms}

\section{a. Histogram cloud types}

Cloud fraction histograms are presented in Fig. 3 for the period September 2003 through August 2005, and suggest three modes of clouds in the WP, CP, and EP. One mode is that of low, marine boundary layer cloud, with top temperatures generally warmer than $280 \mathrm{~K}$. As described by Sarachik (1978), these have bases approximately at $600 \mathrm{~m}$ that extend vertically to about $2 \mathrm{~km}$. Yanai et al. (1973) note that the vast majority of the moisture is contained within this shallow cloud layer, and water vapor and liquid water are transported upward via deep convection. Another dominant mode is that of high cloud, which shows optical depths with a wide range of values. The observation of high cloud with a wide range of optical thickness, ranging from thick convective cores to anvil clouds to thin cirrus, is consistent with observations from ISCCP in Hartmann et al. (2001). However, subtle differences exist in this cloud type, namely that high cloud peaks slightly higher 

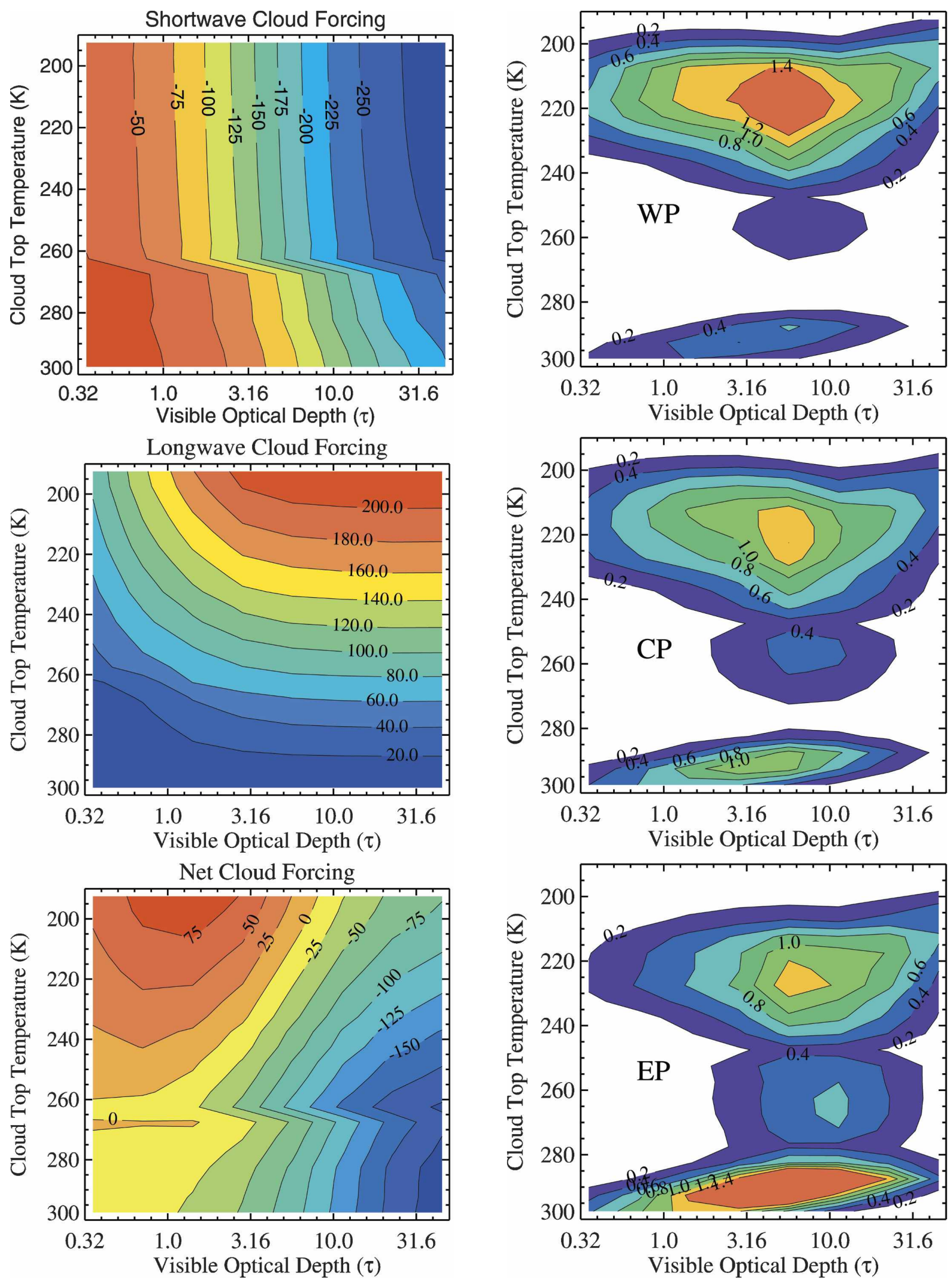

FIG. 2. West Pacific (top) shortwave, (middle) longwave, and (bottom) net cloud TOA radiative forcing, assuming 100\% cloud in each $T-\tau$ bin $\left(\mathrm{W} \mathrm{m}^{-2}\right)$.

FIG. 3. $T-\tau$ histograms of cloud percent for September 2003-August 2005 in (top) WP, (middle) CP, and (bottom) EP. 
up in the troposphere (lower cloud-top temperature) in the WP and CP compared to the EP. Also, the median optical depth of all high cloud in the EP is slightly higher.

Midlevel clouds represent a third, though arguably less important, mode that is particularly prevalent in the EP. This cloud peaks around $260 \mathrm{~K}$ in the EP, and at slightly lower temperatures in the WP and CP. Less attention has been drawn to this population of clouds, and some studies, particularly more conceptual ones, have primarily underscored the two aforementioned modes. Early observational studies, however, such as that by Malkus and Riehl (1964), documented the presence of cumulus congestus clouds at or slightly above the $0^{\circ} \mathrm{C}$ level. Later studies, such as that by Johnson et al. (1999), highlight this middle population of clouds as an important one. Even a two-dimensional cloud modeling study by Liu and Moncrieff (1998) reveals three cloud modes, one of which is located between about 6-7 $\mathrm{km}$, coincident with the melting layer.

To explain the reasons for these three modes, Johnson et al. (1999) suggest that the three layers-one near $2 \mathrm{~km}$, another near $5 \mathrm{~km}$ (near $273 \mathrm{~K}$ ), and the third in the vicinity of 15-16 km (about 1-2 km below the tropopause) - represent three prominent stable layers of the tropical atmosphere (see Fig. 4 for GPS temperatures, corresponding heights, and differences between WP and EP). The enhanced stability in these areas, according to Johnson et al. (1999), stunts vertical cloud growth and promotes divergence and detrainment. As Fig. 4 shows the averaged temperature profiles from September 2004 through July 2005, however, these stability layers are not seen. In MODIS, we see the middle congestus clouds peaking considerably colder than $273 \mathrm{~K}$, at 255-260 K. Johnson et al. (1999) suggests that overshooting above the $0^{\circ} \mathrm{C}$ level occurs because supercooled droplets are in abundance, especially in the ITCZ, and droplets do not become glaciated until 10-15 K colder than $273 \mathrm{~K}$. This is quite consistent with the MODIS identification of a middle cloud population colder than the $273 \mathrm{~K}$ level. It is less clear, however, why the population of congestus is more prominent in the EP. It may have to do with the fact that SST gradients are stronger in the EP, driving stronger surface convergence, and a profile of vertical velocity such that vertical velocity peaks much lower in the troposphere compared to regions such as the WP, where the SST gradients are relatively weak (Back and Bretherton 2006). Even when we examine the conditional probability of seeing congestus cloud given no high cloud (plot not shown), the EP still has more congestus cloud for a given rain rate.
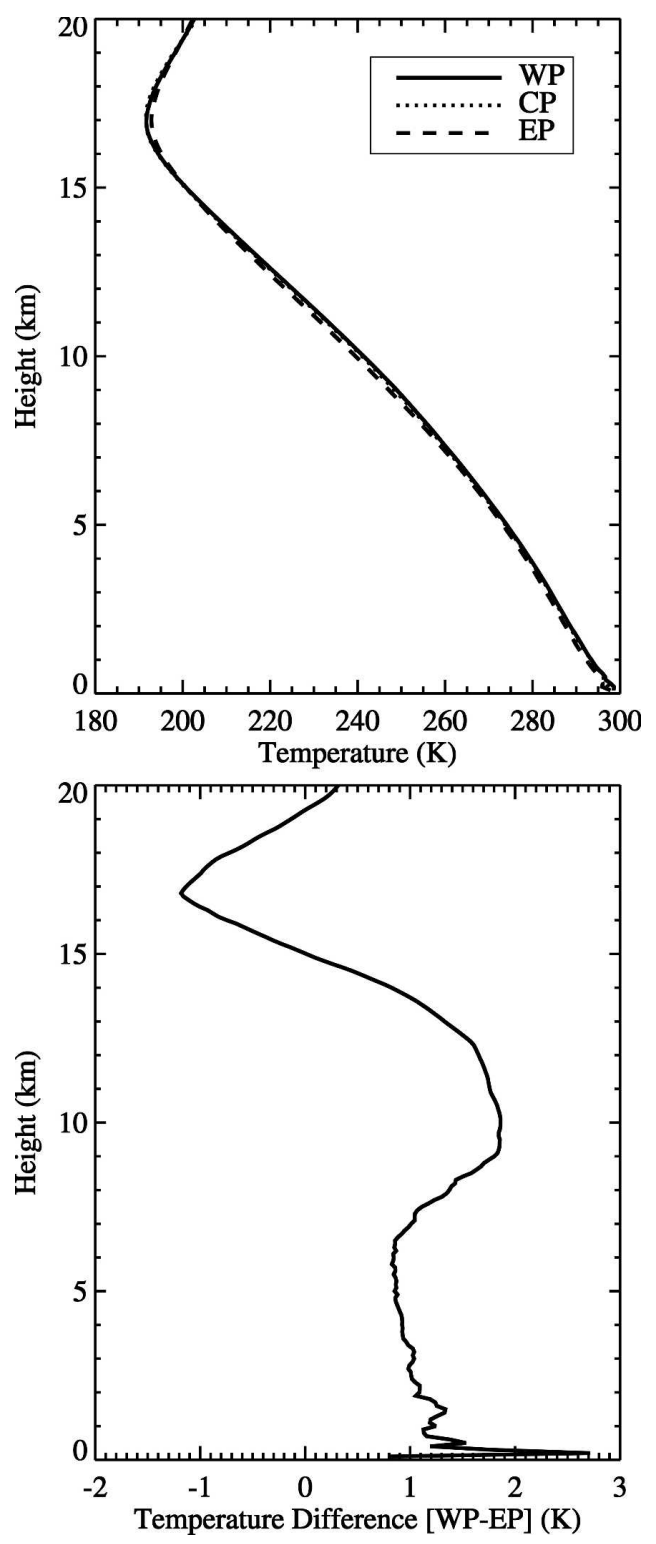

FIG. 4. GPS (top) temperature profiles and (bottom) WP - EP temperature differences for September 2004-July 2005.

\section{b. Cloud forcing by type}

Earlier, we presented $T-\tau$ histograms of SW, LW, and total cloud radiative forcing, assuming 100\% cloud cover in each $T-\tau$ bin. We now use the $T-\tau$ cloud fraction histograms constructed from MODIS data to calculate "average sky" cloud forcing (the term used by Hartmann et al. 2001), to provide information about the actual radiative impact of clouds for the WP, CP, and EP. Multiplying the corresponding overcast cloud forcing histograms (Fig. 2) with actual cloud fraction in each $T-\tau$ box (Fig. 3 ) gives the average cloud radiative effect. 
We define high thin, anvil, and high thick cloud based on their net radiative effects. These clouds all have tops colder than $245 \mathrm{~K}$, and the optical depth ranges are thin (0-4), anvil (4-32), and thick (32-64). Defined in this manner, thin clouds have a TOA warming effect, and anvil and thick cloud a TOA cooling effect. We reserve a separate category for thick cloud because these likely represent deep convective cores.

The average-sky cloud forcing histograms, which hereafter we will refer to as net CRF, are presented in Fig. 5 for the WP, CP, and EP. The net CRF in the EP is much more negative $\left(-51 \mathrm{~W} \mathrm{~m}^{-2}\right)$ than the $\mathrm{CP}(-22$ $\left.\mathrm{W} \mathrm{m}^{-2}\right)$ or WP $\left(-16 \mathrm{~W} \mathrm{~m}^{-2}\right)$ net CRF, partly due to the larger population of low, thick cloud there. Also, the WP (and CP, to a slightly lesser extent) contains much more high, thin cloud, which contributes to a smaller negative net CRF.

Figure 5 also gives the net CRF value for only high cloud in each of the three regions, including only clouds colder than $245 \mathrm{~K}$. The WP and CP have similar high net CRFs, at -7.5 and $-8.4 \mathrm{~W} \mathrm{~m}^{-2}$, respectively. This contrasts with the EP, which has a high net CRF of $-18.2 \mathrm{~W} \mathrm{~m}^{-2}$. The less negative high cloud forcing in the WP stems from differences in thin cloud amount, which will be more clearly demonstrated in the next section. Differences in anvil and thick cloud net CRF will also be addressed later on.

It is also noteworthy at this point to briefly elaborate on the particle size assumptions used in our calculations. As mentioned before, $r_{\text {ice }}$ is assumed to be $30 \mu \mathrm{m}$, and $r_{\text {liquid }} 10 \mu \mathrm{m}$. To quantitatively assess the sensitivity to particle size, high net CRF calculations are also performed with $r_{\text {ice }}=50 \mu \mathrm{m}$ and $r_{\text {ice }}=15 \mu \mathrm{m}$. The net high CRF values with $r_{\text {ice }}=50 \mu \mathrm{m}$ are $-2.5 \mathrm{~W} \mathrm{~m}^{-2}$ for the WP, $-4.3 \mathrm{~W} \mathrm{~m}^{-2}$ for the $\mathrm{CP}$, and $-14.5 \mathrm{~W} \mathrm{~m}^{-2}$ for the EP, respectively. For $r_{\text {ice }}=15 \mu \mathrm{m}$, the values are $-14.0 \mathrm{~W} \mathrm{~m}^{-2}$ for the WP, $-13.9 \mathrm{~W} \mathrm{~m}^{-2}$ for the $\mathrm{CP}$, and $-22.7 \mathrm{~W} \mathrm{~m}^{-2}$ for the EP. It is not surprising that increasing $r_{\text {ice }}$ makes the net high cloud CRF less negative, as this makes clouds less reflective. However, what is important is that the difference between the WP and EP is not affected strongly by assumptions of particle size, and regional differences, as opposed to absolute differences, are at the crux of this study.

\section{High cloud amount versus convective strength}

Simple energy balance indicates that net heating by precipitation in convecting regions is balanced by radiative cooling in adjacent subsidence regions. Deep cumulonimbus clouds carry water vapor from the shallow cloud layer to the upper troposphere, and as they do, the water vapor condenses. It is these cumulonim-
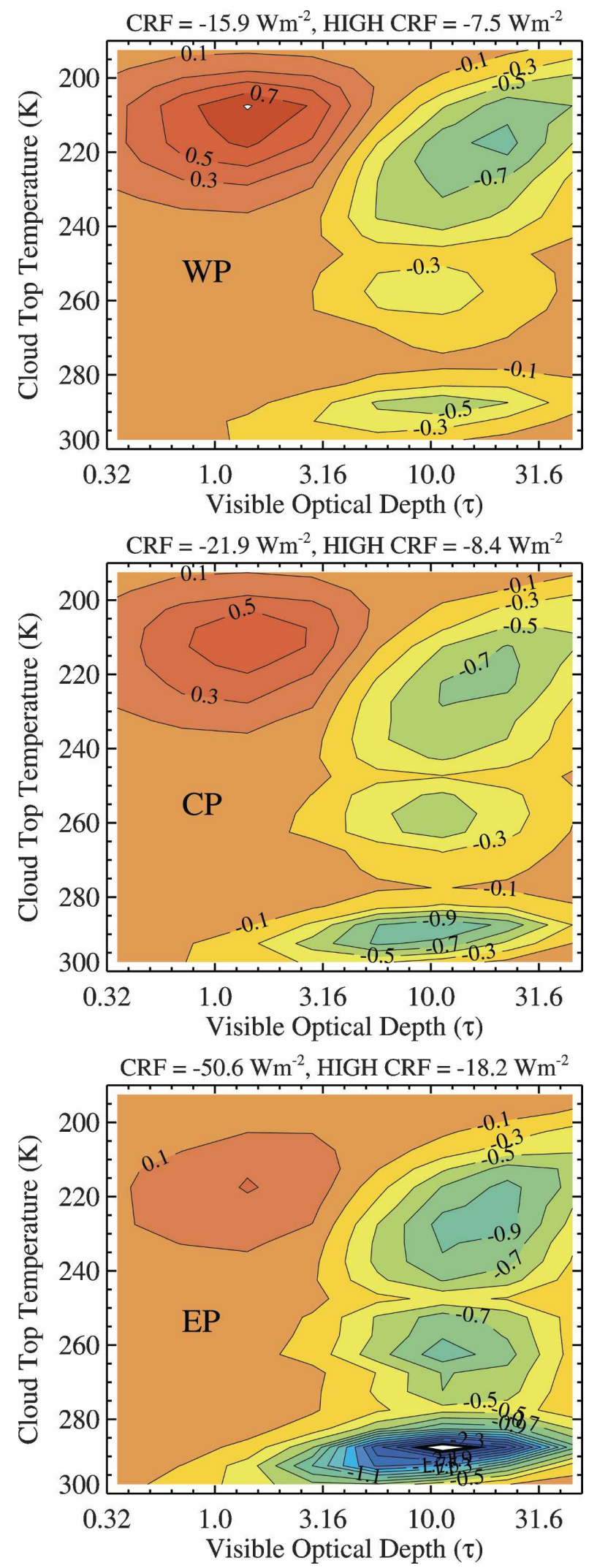

FIG. 5. Cloud radiative forcing contour plots binned by $T-\tau$ in (top) WP, (middle) CP, and (bottom) EP for September 2003August 2005. 

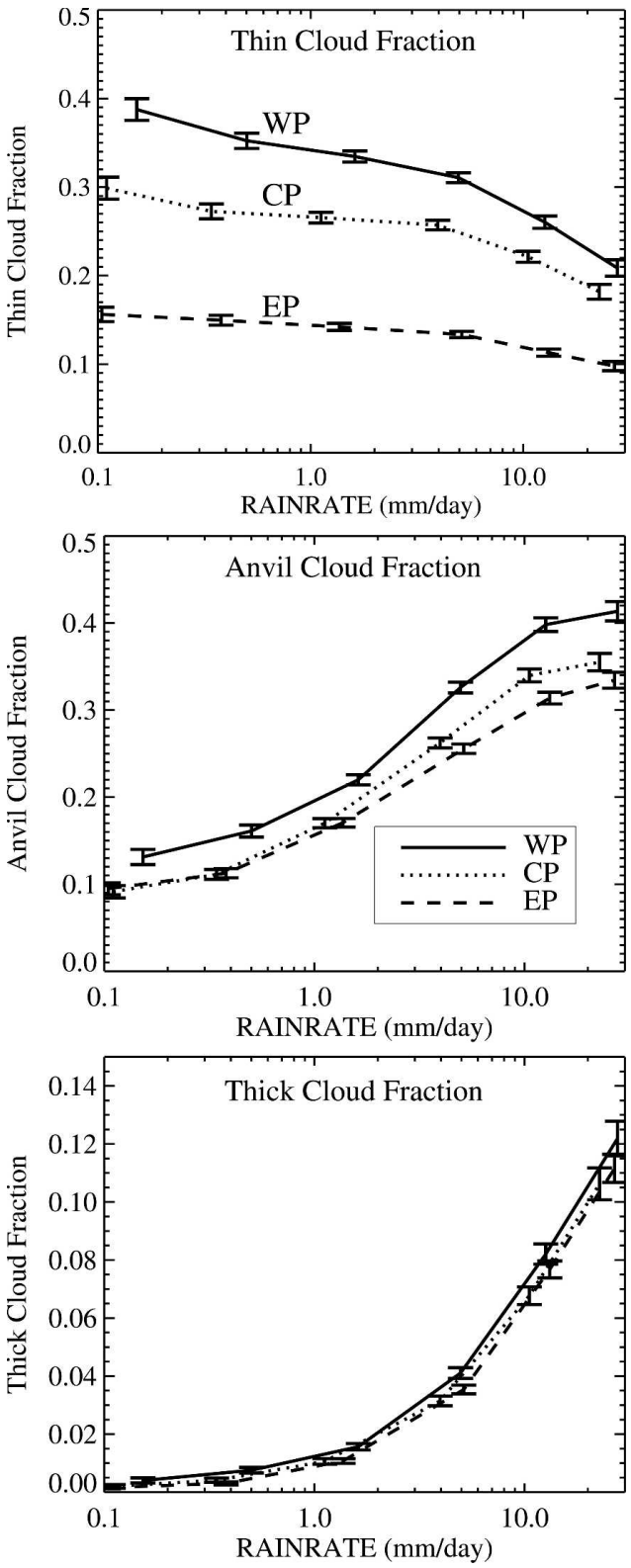

FIG. 6. Thin, anvil, and thick cloud fraction vs rain rate for September 2003-August 2005 (note the different scale for thick cloud fraction).

bus towers that precipitate most heavily, and thus it should follow that rain rate is a good proxy for convection strength. We have composited high cloud with rain rate, with the hope of revealing possible regional differences in characteristics of convection along the ITCZ. By compositing with rain rate, we effectively remove convection strength from the equation, such that differences in structure for a given convective regime can be compared. In Fig. 6, thin, anvil and high thick cloud amount are presented as a function of rain rate, averaged over the 2-yr period of September 2003 through August 2005. Each point represents the following rain-rate percentiles ranges: 1) 2.5th-10th, 2) 10th25th, 3) 25th-50th, 4) 50th-75th, 5) 75th-90th, and 6) 90th-97.5th. Each error bar represents the observed value \pm 3 times the sampling error. The sampling error $S_{E}$ is given by

$$
S_{E}=\frac{\sigma}{\sqrt{N}},
$$

where $\sigma$ is the standard deviation of all $1^{\circ} \times 1^{\circ}$ boxes (3-day aggregates) within each rain-rate percentile regime that have nonzero precipitation rates and at least 200 good data points, and $\mathrm{N}$ the number of $1^{\circ} \times 1^{\circ}$ boxes (3-day aggregates) that fall within each rain-rate regime. Sampling error bars encompassing \pm 3 times the sampling error represent the $99 \%$ confidence interval, assuming normally distributed data. It is important to note that the $1^{\circ} \times 1^{\circ}$ boxes are assumed to be independent of one another, which may not necessarily be the case, such that the error bars might be underestimates.

On the top panel of Fig. 6, we see that for a given rain rate, thin cloud is more than twice as abundant in the WP as in the EP. Also, thin cloud is nearly independent of rain rate. The observed thin cloud fraction decreases slightly with rain rate as anvil and thick cloud increases with rain rate, and this is because as there is more opaque cloud, thin cloud is not as detectible by MODIS, even if it is present.

Anvil cloud is more abundant in the WP than the CP or EP for a given rain rate, though the differences are less dramatic than for thin cloud. Finally, thick cloud in the WP, CP, and EP increases in a very similar manner with rain rate, and it is difficult to distinguish between the three regions. This suggests that thick cloud amount is a very good proxy for rain rate, which could be quite practical for remote sensing purposes, as using OLR alone as a proxy for rain rate can give fallacious results (Berg et al. 2002).

The fact that combined anvil plus thin cloud is much more abundant in the WP per unit of precipitation, despite thick cloud being the same, implies important structural differences in convection in the WP versus the EP. If we understand convective cores to be manifested as thick, high cloud that spreads and thins out with time, then the thick cloud in the WP that spreads out into thinner cloud shields is sustained over larger geographical regions. In a later section, we will show that relative humidity is higher in the WP in the upper troposphere, and perhaps the moister upper troposphere there slows the evaporation of the ice compared 

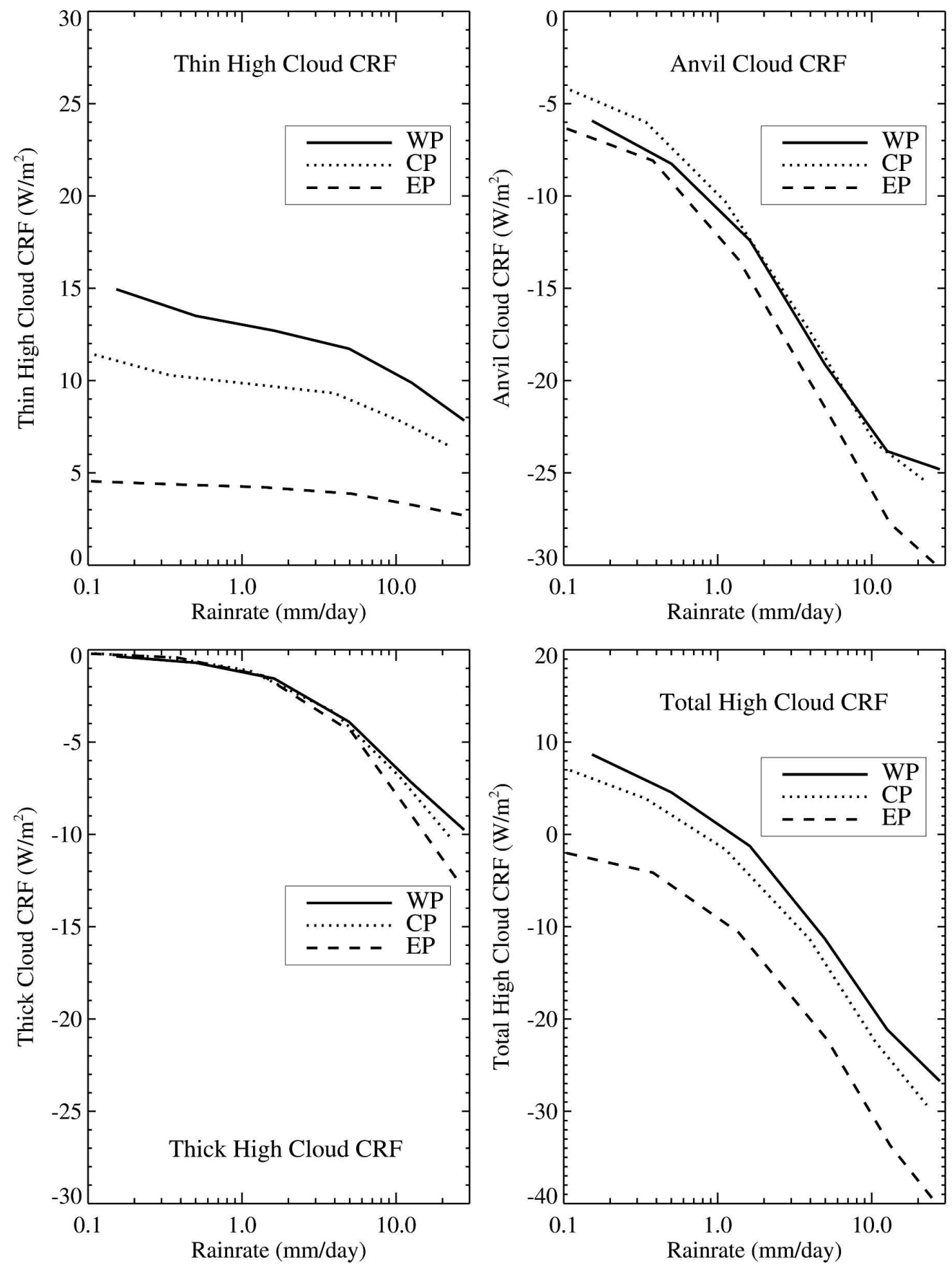

FIG. 7. High cloud radiative forcing vs rain rate for the same period as Fig. 6.

to the EP. It is probable that convection contributes to the observed upper-level relative humidity profiles (Udelhofen and Hartmann 1995). The EP ITCZ is considerably narrower than the WP ITCZ, so that the EP is surrounded by a much drier upper-level environment. The EP is thus more readily influenced by the surrounding dry regions, which could be less conducive to maintenance of anvil and thin high cloud. Entrain- ment of non-ITCZ air into the EP in the upper troposphere could partly explain the lower anvil and thin cloud amount. At present, we cannot compute accurate moisture budgets for these regions, however.

We also examine the TOA radiative impacts of thin, anvil, and thick cloud by compositing them with rain rate. Figure 7 shows that thin cloud increases TOA radiation, and anvil and thick cloud reduce the TOA 
energy budget. For a given rain rate, the CRF of thin high cloud is approximately $10 \mathrm{~W} \mathrm{~m}^{-2}$ higher in the WP versus the EP. With increasing rain rate, the CRF of anvil and thick cloud becomes more negative, as these cloud types become more abundant. The anvil and thick net CRF in the WP and EP are nearly indistinguishable from one another, however, despite the presence of more anvil cloud in the WP. This is because even though the SW effect is stronger for anvil cloud (because the anvil cloud fraction is greater) for a given rain rate in the WP (not shown), the LW effect is also stronger (also not shown), since anvil cloud is slightly colder in the WP.

Finally, the bottom right panel of Fig. 7 shows that the total high CRF is considerably more negative for the EP for a given rain rate, which we can safely say is mostly due to much less thin, high cloud there, since the CRF due to the other high cloud types (anvil and thick) is very similar in the WP and EP for a given rain rate. Thus, the structural differences in convection in the WP and EP also have significant implications for the energy balance at the top of the atmosphere.

\section{High cloud-top temperature versus rain rate}

We now present thin, anvil, and thick cloud-top temperature versus rain rate in Fig. 8. It is clear that all high cloud types in the WP and CP are systematically about $5 \mathrm{~K}$ colder than the $\mathrm{EP}$, for a given rain rate. Once again, for quality assurance purposes, these data only include each 3 -day $1^{\circ} \times 1^{\circ}$ box for which at least the cloud fraction is greater than zero, at least 200 good $5-\mathrm{km}$ data points are present, and the rain rate is nonzero. For all rain rates during the September 2003 through August 2005 period, the median cloud-top temperatures of thin clouds are $\mathrm{WP}=217.4 \mathrm{~K}, \mathrm{CP}=$ 217.6 K, and $\mathrm{EP}=222.8 \mathrm{~K}$. For anvil cloud, the respective temperatures are $219.4,220.8$, and $224.3 \mathrm{~K}$, and for thick cloud 212.1, 214.3, and 218.5 K. Thus, WP thin and anvil clouds are approximately $5 \mathrm{~K}$ colder than in the $\mathrm{EP}$, and thick cloud about $6 \mathrm{~K}$ colder.

A few points can be made about these observations. First, as expected, thick convective cores penetrate highest in the atmosphere, and anvil clouds detrain from these cores at a lower level. Thin cloud is only slightly colder than the anvil cloud, which seems to lend credence to a notion that it is related to the anvil cloud. It is important to note, however, that MODIS does not see tropopause cirrus at all, as it is too optically thin. According to Dessler and Yang (2003), the optical depth cutoff for MODIS is 0.02 , and while the subvisual tropopause cirrus have optical depths less than 0.03 (McFarquhar et al. 2000), they are often optically thin-
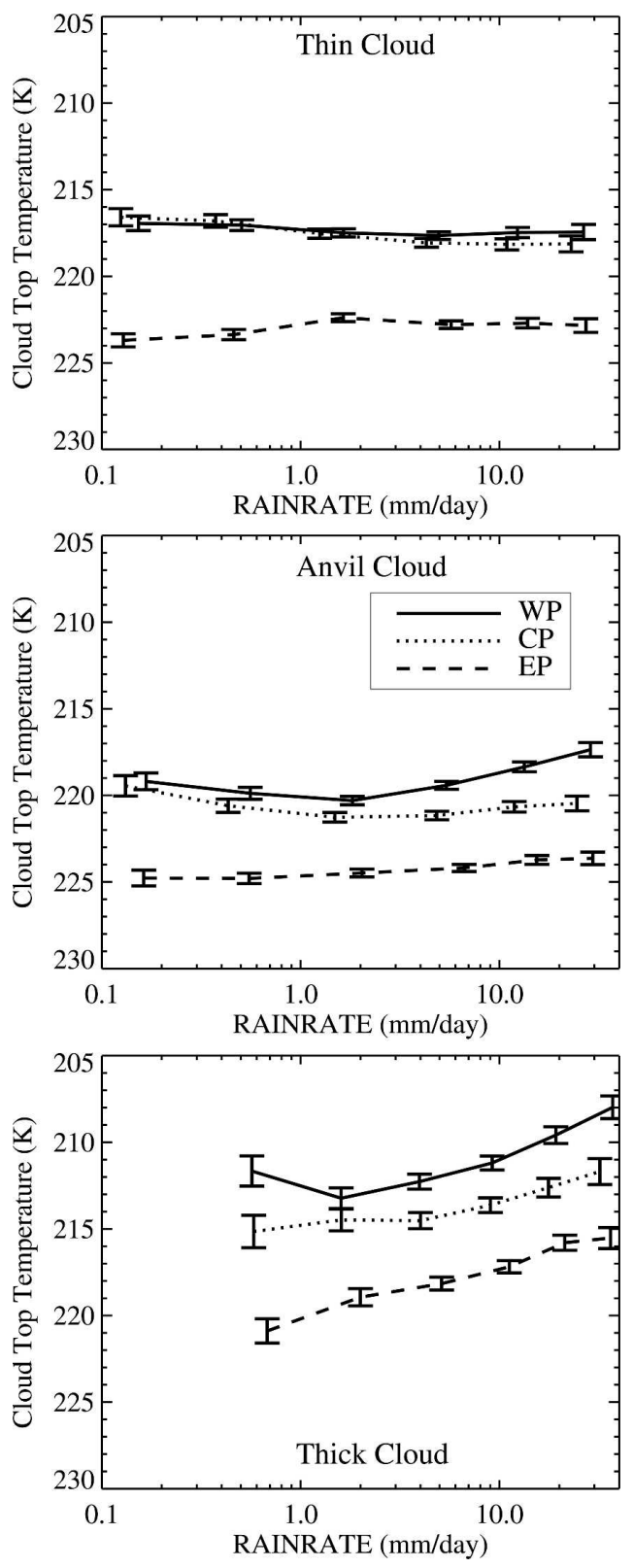

FIG. 8. Cloud-top temperature vs rain rate for (top) thin, (middle) anvil, and (bottom) thick high cloud for September 2003-August 2005.

ner than that. One can view the evolution of convection such that anvil cloud detrains from core clouds, and over time, thin cloud is the residual of the anvil cloud as it spreads and thins out away from the convective cores, although some high thin cloud can be generated by waves (e.g., Boehm and Verlinde 2000). It seems that MODIS can detect thin cloud at realistic temperatures, compared to satellite estimates based on thermal imaging alone, for which the temperature depends on emis- 
sivity. The $\mathrm{CO}_{2}$-slicing method utilized by MODIS, on the other hand, does not require an emissivity estimate.

It is noteworthy that anvil and thin cloud-top temperature seem to show no clear relationship with rain rate, whereas thick cloud (save the lowest rain rates in the WP) seems to get colder with increasing rain rate, at least in the EP. This perhaps is consistent with the notion that the thick cloud is convectively driven, and since rain rate is a proxy for convection strength, we might expect that the deepest convection be more sensitive to the SST.

\section{Clear-sky divergence calculations in the upper troposphere}

We wish to better understand cloud-top temperature differences in the WP and EP, and to ask how the cloud-top temperature is determined. We explore both the PUSH and PULL mechanisms; the former suggests that the altitude of anvil and thick clouds is driven by buoyancy, while the latter argues for clear-sky radiation being the key factor. In this section, we focus on data used to explore the PULL mechanism. Calculation of clear-sky convergence profiles requires moisture and temperature profiles, that are then used to calculate clear-sky cooling rates and vertical velocity $(\omega)$ profiles.

The Microwave Limb Sounder (MLS), aboard the Aura satellite, uses the $190 \mathrm{GHz}$ channel to measure upper-level water vapor mixing ratios. There are 22 levels between 316 and $0.1 \mathrm{hPa}$, with measurements made in the upper-tropospheric region of interest at 316, 215, 147, and $100 \mathrm{hPa}$ (Livesey et al. 2005). This corresponds to a vertical resolution range of 2.7-3.0 $\mathrm{km}$. This resolution in the upper troposphere with MLS is superior compared to more conventional measurements of upper-level relative humidity from radiosondes, whose spatial resolution is spotty, and satellites, whose vertical resolution is coarse (Sassi et al. 2001). Vertical resolution in the upper troposphere is important for moisture for clear-sky divergence calculations. Also, MLS can measure upper-tropospheric moisture in clear and cloudy regions, as opposed to nadir satellite measurements using thermal infrared, which are limited to clear skies. Data from MLS aboard the Aura satellite are available from September 2004 onward.

Vertical temperature profiles are available from Global Positioning System (GPS) data, with $0.5 \mathrm{~K}$ precision. Though GPS data are available well before September 2004, we start from September 2004 to overlap with the Aqua data. This is a navigation system that contains 24 satellites. Major advantages of GPS include long-term stability, good vertical resolution, all-weather capability, and global coverage. Atmospheric refractiv- ity fields are utilized, allowing conversion to profiles of temperature and pressure (Schmidt et al. 2004). The largest temperature errors occur near the surface and at $8 \mathrm{~km}$, and are 0.5 and $0.2 \mathrm{~K}$, respectively. Errors fall to $0.1 \mathrm{~K}$ in the majority of the stratosphere (Kursinski et al. 1997).

The same radiative transfer model used for CRF calculations is used to compute atmospheric profiles of clear-sky radiative cooling rates, which require temperatures and mixing ratios as inputs. GPS temperatures are interpolated onto the 1000 pressure levels in the model; the layers between each level contain approximately equal mass. Between 0.1 and $147 \mathrm{hPa}$, MLS mixing ratios are interpolated onto the model pressure levels. For mixing ratios between 147 and 316 $\mathrm{hPa}$, a polynomial fit of order three is used to interpolate data onto the model pressure levels. Between 316 and $375 \mathrm{hPa}$, a linear fit is made, and below this, an idealized tropical profile (with specific humidity) is used, from McClatchey et al. (1971).

Once the radiative cooling rates are calculated, they are used to calculate the diabatic omega $(\omega)$ profiles from the following relationship, which is derived from the thermodynamic energy equation (Holton 1992):

$$
\omega=\frac{-Q(p) p c_{p}}{R_{D} T}\left(1-\frac{p c_{p}}{R_{D} T} \frac{\partial T}{\partial p}\right)^{-1} .
$$

In (3), Q(p) is the radiative cooling rate as a function of pressure, $c_{p}$ is the specific heat at constant pressure $\left[=1004 \mathrm{~J} \mathrm{~K}^{-1} \mathrm{~kg}^{-1}\right], \mathrm{R}_{\mathrm{D}}$ is the dry air gas constant [ $\left.=287 \mathrm{~J} \mathrm{~K}^{-1} \mathrm{~kg}^{-1}\right], \mathrm{T}$ is the absolute temperature, and $\omega$ is the vertical velocity in pressure coordinates.

Next, the horizontal divergence is calculated from the continuity equation, which is given by

$$
\operatorname{div}_{H}=-\frac{\partial \omega}{\partial p} .
$$

In (4), $\operatorname{div}_{H}=\partial u / \partial x+\partial v / \partial y$. Because of the derivative, the estimated divergence is quite noisy, and a smoothed divergence profile is computed for each region by averaging divergence into $5^{\circ}$ temperature bins (temperature being the vertical coordinate) corresponding to the temperature bins used for the MODIS data. Vertical profiles of relative humidity, cooling rates, $\omega$ profiles, and smoothed divergence profiles are discussed in more detail in the next section.

\section{Relative humidity, cooling rate, $\omega$, and clear-sky convergence profiles}

Composite relative humidity profiles from September 2004 through July 2005 for the WP, CP, and EP are 


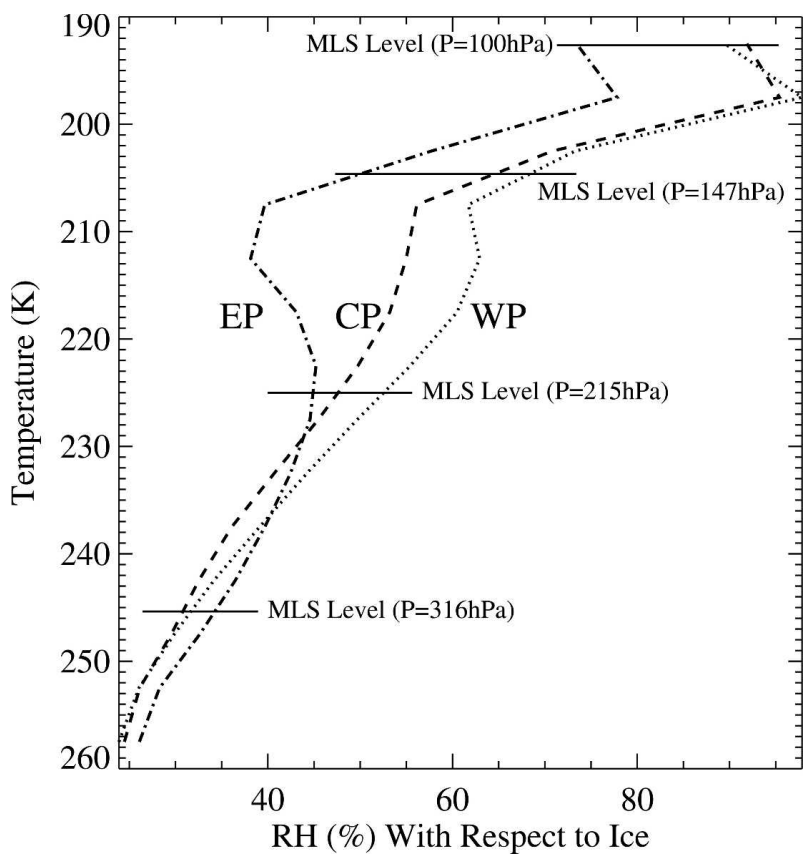

FIG. 9. September 2004-July 2005 relative humidity with respect to ice in WP, CP, and EP. Also shown are MLS levels.

shown in Fig. 9. The focus here is in the temperature range where anvil clouds detrain, which occurs between about 215 and $225 \mathrm{~K}$. In the EP and WP profiles a secondary peak in relative humidity occurs at about these temperatures. The peak in relative humidity in the WP is larger in magnitude and peaks at a lower temperature than the EP. These differences in relative humidity peak temperature and amplitude are interesting, and might be related to the fact that there are simply more anvil and thin clouds in the WP than in the EP.

Clear-sky radiative cooling rate profiles are presented in Fig. 10, and show that below $250 \mathrm{hPa}$, cooling rates are roughly constant at around $2 \mathrm{~K}_{\text {day }}{ }^{-1}$. Above this layer, clear-sky radiative cooling rates drop off sharply. Hartmann and Larson (2002) argue that this is because of the Clausius-Clapeyron relationship, which states that the saturation vapor pressure depends only on temperature. Clear-sky emission from the upper troposphere comes from the rotational lines of water vapor, and depends strongly on vapor pressure. The sharp decreases of clear-sky radiative cooling rate profiles above $250 \mathrm{hPa}$ occur because of low absolute temperatures there and consequently low vapor pressures. The large decrease in clear-sky radiative cooling rates corresponds to a mass convergence at this temperature, and this balances divergence from convective regions at the same temperature. It is this circulation that induces detrainment of the majority of anvil cloud.

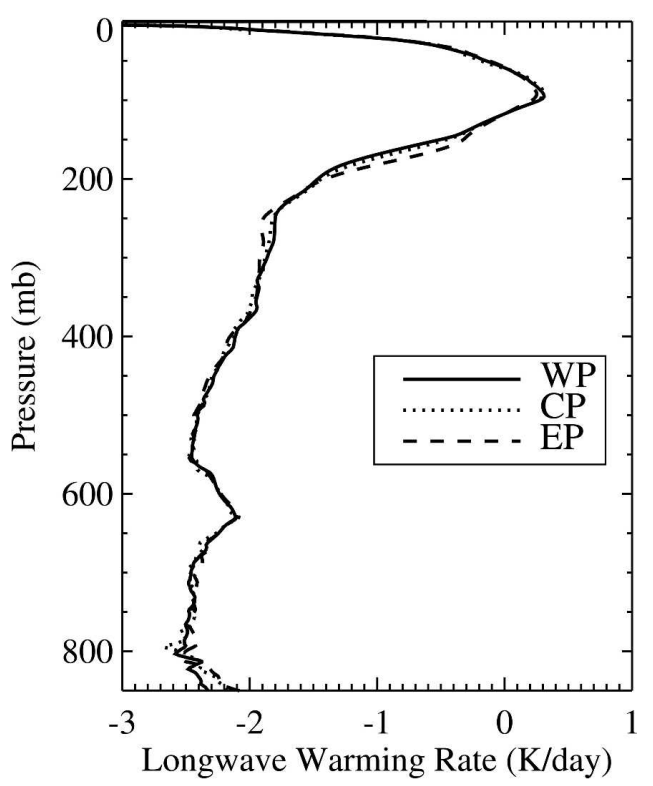

FIG. 10. Calculated clear-sky radiative warming rates for WP, $\mathrm{CP}$, and $\mathrm{EP}$.

Profiles of clear-sky $\omega$ are shown in Fig. 11, and indicate fairly strong subsidence below about $250 \mathrm{hPa}$ (on the order of $40 \mathrm{mb} /$ day), and decreasing sinking motion above this level. The $Q=0$ level, which is the level at which clear-sky radiative cooling is zero, is around 125 $\mathrm{hPa}$ (see Fig. 10). This is below the tropopause, which is at approximately $95 \mathrm{hPa}$ in all three regions.

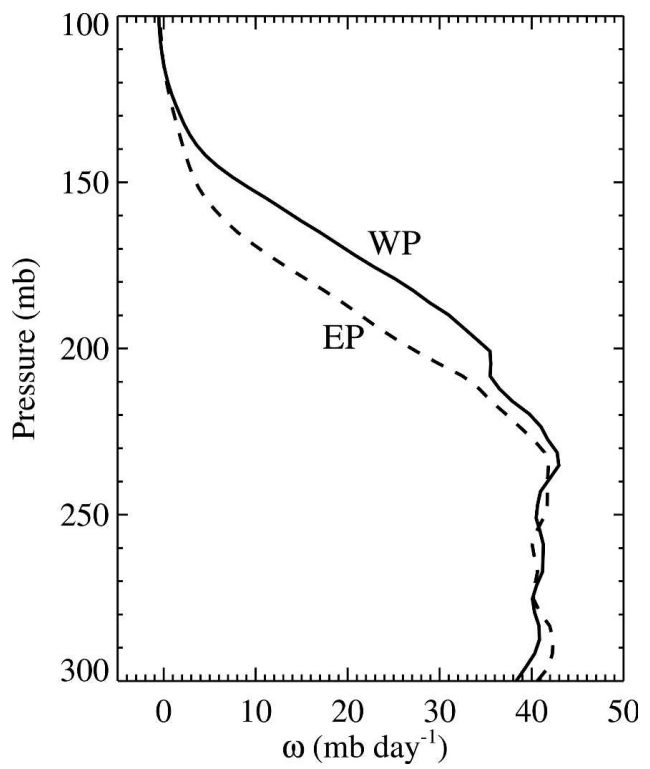

FIG. 11. Vertical velocity in pressure coordinates $(\omega)$ necessary to balance clear-sky radiative cooling for September 2004-July 2005. 


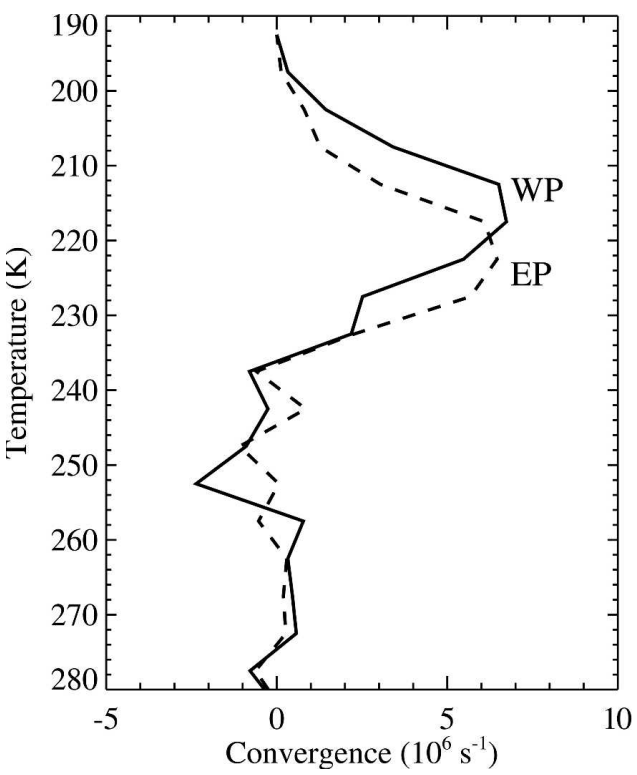

FIG. 12. Binned clear-sky convergence profiles for WP and EP for September 2004-July 2005.

Smoothed clear-sky convergence profiles are shown in Fig. 12. Clear peaks appear in the upper troposphere in the WP and EP, roughly corresponding to the peaks in upper-level relative humidity. To quantify the differences in the WP and EP, a convergence-weighted temperature $\left(\mathrm{T}_{\mathrm{C}}\right)$ is calculated from the following relationship:

$$
T_{C}=\frac{1}{\bar{C} \Delta T} \int_{190 \mathrm{~K}}^{240 \mathrm{~K}} C(T) T d T,
$$

where $C(T)$ is the smoothed convergence, $\bar{C}$ is the mean convergence in the layer from 240 to $190 \mathrm{~K}$, and $\Delta T=50 \mathrm{~K}$. Convergence-weighted temperature provides a quantitative measure of the temperature at the peak of convergence, and is $216.6 \mathrm{~K}$ in the WP and $220.2 \mathrm{~K}$ in the EP for the period of September 2004 through July 2005. As we shall see in a later section, these differences in clear-sky convergence correspond rather well with differences in anvil cloud-top temperature measured by MODIS.

In an attempt to quantify why $T_{C}$ is about $3.6 \mathrm{~K}$ colder in the WP versus the EP, we explore the relative importance of specific humidity and temperature profiles. We do this by pairing the WP and EP temperature and specific humidity profiles in all possible combinations and computing the corresponding $\mathrm{T}_{\mathrm{C}}$. Table 1 indicates that the specific humidity difference is more important than the temperature, but the temperature is also a factor. Figure 4 shows that the WP has a larger lapse rate in the region above $12 \mathrm{~km}$, or colder
TABLE 1. Convergence-weighted temperature $\left(T_{C}\right)$ for WP and EP specific humidity and temperature profiles.

\begin{tabular}{lcc}
\hline \hline & $\begin{array}{c}\text { WP specific } \\
\text { humidity }\end{array}$ & $\begin{array}{c}\text { EP specific } \\
\text { humidity }\end{array}$ \\
\hline WP temperature profile & $216.6 \mathrm{~K}$ & $219.2 \mathrm{~K}$ \\
EP temperature profile & $218.1 \mathrm{~K}$ & $220.2 \mathrm{~K}$ \\
\hline
\end{tabular}

than about $225 \mathrm{~K}$. An idealized tropical profile from McClatchey et al. (1971) was used below the MLS levels. While reanalysis data below the MLS region would perhaps be preferred, sensitivity studies were performed (figures not shown), and suggested that moisture further down in the troposphere does not matter very much at all compared to moisture closer to $\mathrm{T}_{\mathrm{C}}$.

\section{Testing the PUSH mechanism}

The notion behind the PUSH mechanism is that the surface drives convection, by assuming that parcels of air, so long as they retain positive buoyancy, ascend undiluted until they become negatively buoyant in the upper troposphere (Riehl and Malkus 1958; Riehl and Simpson 1979). The level of neutral buoyancy in the upper troposphere is reached at the temperature aloft in which environmental $\theta_{E}$ is the same as $\theta_{E}$ at the LCL. We refer to this intersection temperature as $T_{\text {INT. }}$. We calculate $T_{\mathrm{INT}}$ first by calculating $\theta_{E}$ profiles for the $\mathrm{WP}, \mathrm{CP}$, and EP, and then simply determining the intersecting point in the upper troposphere. Given this procedure, parcels in the WP have the potential to ascend higher, as $\theta_{E}$ at the LCL is $365.8 \mathrm{~K}$, versus $358.4 \mathrm{~K}$ in the EP (these are calculated assuming that the LCL temperatures are $6 \mathrm{~K}$ lower than the SSTs in each of the regions - the surface relative humidity in the EP and WP are very similar to one another, according to the Comprehensive Ocean-Atmosphere Dataset, making this an acceptable assumption). For the same period (September 2004 through July 2005), $T_{\mathrm{INT}}$ is $192.9 \mathrm{~K}$ in the WP, $194.9 \mathrm{~K}$ in the CP, and $199.8 \mathrm{~K}$ in the EP. These temperatures are significantly lower than $T_{\mathrm{ANVIL}}$ (median anvil cloud-top temperature), by $20 \mathrm{~K}$ or more, and even $T_{\mathrm{THICK}}$ (median thick cloud-top temperature). Therefore, the surface air in both the EP and WP has enough energy to rise undiluted to well above the level where the anvil cloud is concentrated. One must assume a particular entrainment spectrum for plumes in order to explain the existence of the anvils. This has not been done for this particular study, however. The clearsky radiative cooling profile can explain the temperature of the anvil clouds much more fundamentally. 


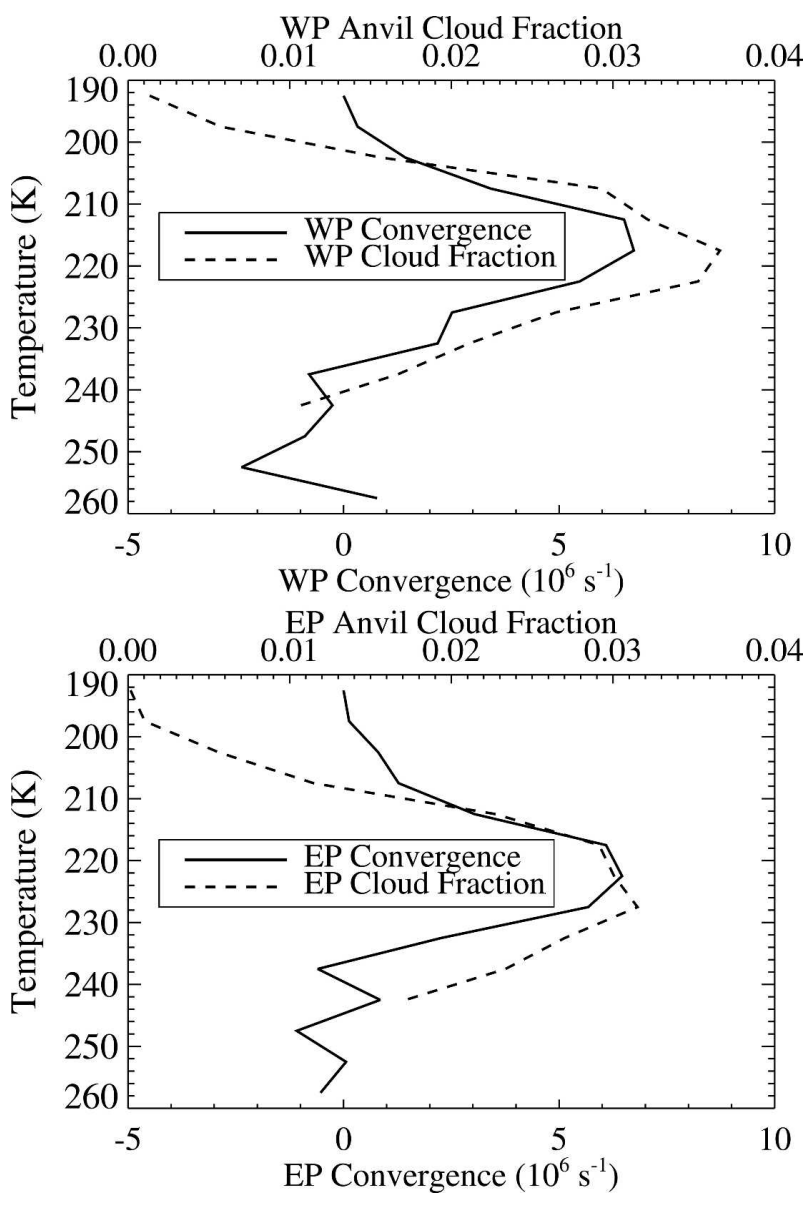

FIG. 13. Clear-sky convergence and anvil cloud fraction for (top) WP and (bottom) EP for September 2004-July 2005.

\section{Comparing the push and pull mechanisms}

It was discussed previously that clear-sky convergence profiles support a circulation connecting clear and adjacent convective regions. The peak of the clearsky convergence should therefore correspond to the detrainment level of anvil cloud. To investigate this, we examine a subset of data, from September 2004 through July 2005, during which we have GPS, MLS, and MODIS data. In Fig. 13, we present the clear-sky convergence profiles along with the anvil cloud fraction profiles for the WP and EP, both as functions of temperature. The peak in upper-level convergence lines up well with the peak in anvil cloud amount in all three regions (only the WP and EP are shown for clarity). The differences in $\mathrm{T}_{\mathrm{ANVIL}}$ in the WP and EP correspond well to those of the clear-sky convergence peak. Thus, vertical profiles of convergence and observed anvil cloud fractions are related to one another.

To further quantify whether or not $T_{C}$ is actually a good predictor of $\mathrm{T}_{\mathrm{ANVIL}}$, we subdivide the data into

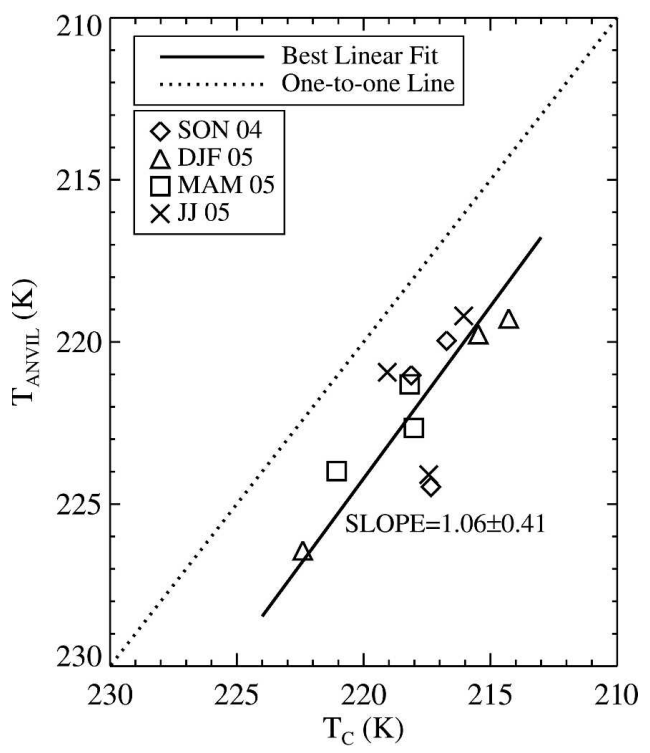

FIG. 14. Seasonal median anvil cloud-top temperature ( $\left.T_{\text {ANVIL }}\right)$ vs seasonal convergence-weighted temperature $\left(T_{C}\right)$.

seasonal datasets, so as to increase the number of samples with which to evaluate the statistical validity of the relationships between $T_{C}$ and $T_{\mathrm{ANVIL}}$. We present $T_{\text {AnVIL }}$ versus $T_{C}$ in Fig. 14 , as well as the one-to-one line of these two variables. Principal component analysis is performed in this plot and subsequent ones to calculate the slopes, which makes no assumptions of dependent or independent variables. The slope of the best linear fit is $1.06 \pm 0.41$, which means that a oneto-one relationship between $T_{\mathrm{ANVIL}}$ and $T_{C}$ cannot be ruled out. Here $T_{\mathrm{ANVIL}}$ is only about 3 to $4 \mathrm{~K}$ warmer than $T_{C}$. Figure 14 shows that the peak in clear-sky convergence corresponds well to $T_{\mathrm{ANVIL}}$, such that the clear-sky radiative profile seems to drive anvil cloud detrainment.

The PULL mechanism certainly seems to be able to predict the level of anvil cloud detrainment. Can the PUSH mechanism also be used to predict the level of convective detrainment? We address this first by plotting $T_{\text {ANVIL }}$ versus $T_{\text {INT }}$ for the seasonal data (Fig. 15), and immediately see, as suggested earlier, that $\mathrm{T}_{\text {INT }}$ is much lower (by $20 \mathrm{~K}$ or more) than $T_{\mathrm{ANVIL}}$. The slope of the best linear fit line is $0.59 \pm 0.41$, so that it seems that $T_{\text {INT }}$ does not explain where anvil clouds are detraining.

But, does $T_{\text {INT }}$ have any bearing on how high the thickest clouds get? We might expect more of a linear relationship between the thickest high clouds and $\Theta_{E}$ near the surface since they represent the tallest convective cores, which are least affected by detrainment. Figure 16 shows both $T_{\mathrm{THICK}}$ versus $T_{\mathrm{INT}}$ and the 90th 


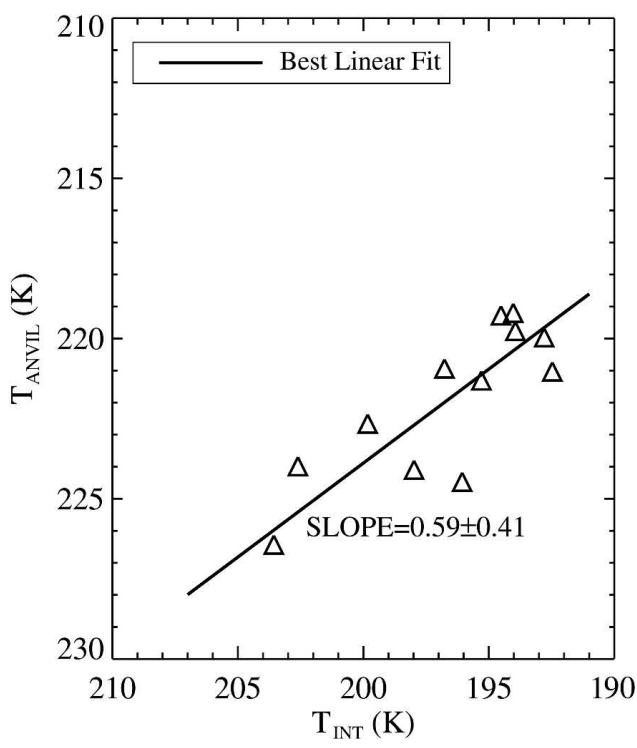

FIG. 15. Seasonal median anvil cloud-top temperature ( $\left.T_{\text {ANVIL }}\right)$ vs seasonal intersection temperature ( $T_{\text {INT }}$ is the temperature in the upper troposphere where $\Theta_{E}$ is the same as $\Theta_{E}$ at the LCL).

percentile of the coldest thick clouds from MODIS $\left(T_{\text {THICK } \_90}\right)$ versus $T_{\text {INT }}$. We immediately see that $T_{\text {INT }}$ is significantly colder than $T_{\mathrm{THICK}}$ by approximately $10-15 \mathrm{~K}$, but that the slope of the best linear fit is 0.96 \pm 0.41 , so a one-to-one relationship cannot be ruled out. The relationship between $T_{\text {INT }}$ and $T_{\text {THICK }-90}$ is

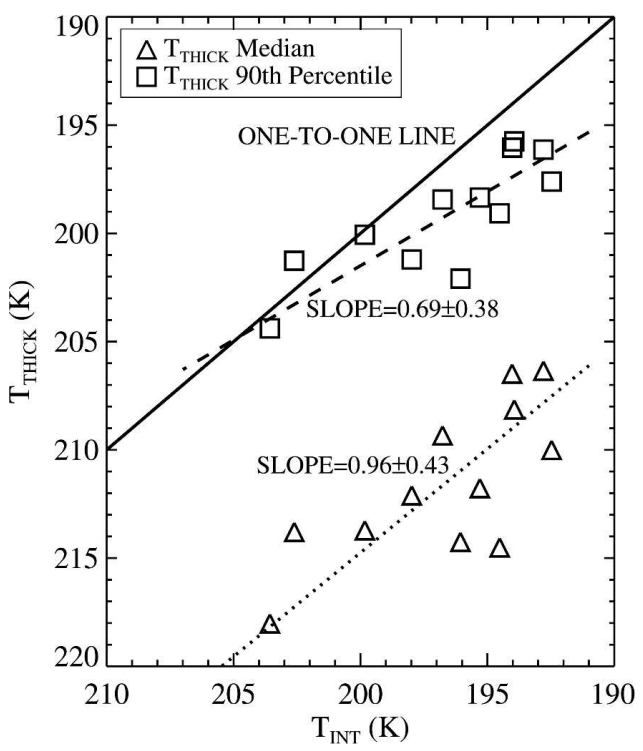

FIG. 16. Seasonal thick cloud temperature $\left(T_{\mathrm{THICK}}\right)$ and 90 th percentile of $T_{\text {THICK }}$ vs seasonal intersection temperature $\left(T_{\text {INT }}\right.$ is the temperature in the upper troposphere where $\Theta_{E}$ is the same as $\Theta_{E}$ at the LCL). more convincing, especially since the 90th percentile of the thick clouds often makes it to $\mathrm{T}_{\mathrm{INT}}$. The slope of the line is $0.69 \pm 0.38$. Also, the fact that $T_{\text {INT }}$ and $T_{\text {THICK_90 }}$ are close to one another does seem to suggest that there is a relationship between the two. The lowlevel $\theta_{E}$ thus does seem to constrain the coldest level of the convective cores, as we would expect, but the anvil cloud temperature is better predicted by the clear-sky convergence.

\section{Conclusions}

We have examined structural characteristics of tropical convection in the ITCZ of the North Pacific. We have shown three modes of clouds in the WP, CP, and $\mathrm{EP}$, namely trade cumulus clouds, midlevel congestus clouds, and deep convective cores and the associated detrained anvil and thin clouds. Low cloud is more prevalent in the EP, where the domain chosen is surrounded by low SST and abundant stratocumulus cloud. Congestus cloud is also somewhat more prevalent in the EP. This may be a result of the fact that convection in the EP is more strongly driven by surface convergence (Back and Bretherton 2006).

For a given rain rate, high thin cloud is nearly twice as abundant in the WP as in the EP, and this makes the TOA radiative forcing due to this cloud considerably higher in the WP, on the order of $10 \mathrm{~W} \mathrm{~m}^{-2}$. Anvil cloud fraction for a given rain rate is also somewhat higher in the WP compared to the EP, though because the anvil cloud is colder in the WP, the net radiative forcing of anvil cloud is about the same in the two regions. Thick cloud amount has the same relationship with rain rate in the WP, $\mathrm{CP}$, and $\mathrm{EP}$, making it a very good proxy for rain rate.

The differences in high cloud radiative forcing in the WP and EP stem primarily from differences in high thin cloud amount. Thin and anvil clouds are systematically about $5 \mathrm{~K}$ colder in the WP versus the EP, and thick clouds about $6 \mathrm{~K}$ colder. Thick clouds are the coldest, and anvil and thin clouds are observed at similar temperatures. It seems that anvil clouds detrain from convective cores, and over time thin cloud is the residual of the anvil cloud.

We speculate that higher amounts of thin and anvil cloud in the WP are due to the broad structure of the ITCZ there, whereas the domain chosen for the EP is surrounded by subsidence regions, whose freetropospheric air is drier, and may entrain somewhat into the EP convective zones.

We also examine how cloud-top temperature is determined by examining the PUSH and PULL mechanisms. To examine the PULL mechanism, which states 
that convective detrainment is driven by clear-sky convergence, we first examine upper-tropospheric relative humidity. It is higher in the WP, and peaks at a lower temperature than the EP. The relative humidity structure seems to be consistent with the abundance of anvil and thin cloud, with greater humidity associated with more high cloud. Also, seasonal data suggest that the temperature weighted by clear-sky convergence is a good predictor of $T_{\text {ANVIL }}$. The radiative cooling profiles depend on the temperature and moisture profiles, which are determined by a mixture of radiation, convection, and large-scale forcing, so that it is not possible to determine causality from such a diagnostic analysis. The large-scale motion fields may in fact be responsible for the differences between the WP and EP. It is known that the vertical velocity profile is shallower in the EP than the WP. Also, the PULL mechanism gives a simpler prediction of the anvil cloud, as it can be computed from the clear-sky radiative cooling profile. Finally, unlike the PUSH mechanism, PULL requires no assumptions about entrainment profiles.

In examining the PUSH mechanism, the temperature where near-surface air achieves neutral buoyancy is much colder than $T_{\text {ANVIL }}$, and $\Theta_{E}$ does not seem to control $T_{\text {ANVIL }}$. The thickest, coldest clouds (the 90th percentile of the thick clouds) can make it to $T_{\text {INT }}$, so near-surface $\Theta_{E}$ might be controlling the altitude of the coldest convective cores.

Acknowledgments. This work was supported by NASA Grant NNG05GA19G.

\section{REFERENCES}

Back, L. E., and C. S. Bretherton, 2006: Geographic variability in the export of moist static energy and vertical motion profiles in the tropical Pacific. Geophys. Res. Lett., 33, L17810, doi:10.1029/2006GL026672.

Berg, W., C. Kummerow, and C. A. Morales, 2002: Differences between east and west Pacific rainfall systems. J. Climate, 15, 3659-3672.

Boehm, M. T., and J. Verlinde, 2000: Stratospheric influence on upper tropospheric tropical cirrus. Geophys. Res. Lett., 27, 3209-3212.

Dessler, A. E., and P. Yang, 2003: The distribution of tropical thin cirrus clouds inferred from Terra MODIS data. J. Climate, 16, $1241-1247$.

Folkins, I., M. Loewenstein, J. Podolske, S. J. Oltmans, and M. Proffitt, 1999: A barrier to vertical mixing at $14 \mathrm{~km}$ in the tropics: Evidence from ozonesondes and aircraft measurements. J. Geophys. Res., 104, 22 095-22 102.

— S. J. Oltmans, and A. M. Thompson, 2000: Tropical convective outflow and near surface equivalent potential temperatures. Geophys. Res. Lett., 27, 2549-2552.

Fu, Q., and K. N. Liou, 1993: Parameterization of the solar radiative properties of cirrus clouds. J. Atmos. Sci., 50, 2008-2025.
Harrison, E. F., P. Minnis, B. R. Barkstrom, V. Ramanathan, R. D. Cess, and G. G. Gibson, 1990: Seasonal variation of cloud radiative forcing derived from the Earth radiation budget experiment. J. Geophys. Res., 95, 18 687-18 703.

Hartmann, D. L., and K. Larson, 2002: An important constraint on tropical cloud-climate feedback. Geophys. Res. Lett., 29, 1195, doi:10.1029/2002GL015835.

_ , L. A. Moy, and Q. Fu, 2001: Tropical convection and the energy balance at the top of the atmosphere. J. Climate, 14, 4495-4511.

Holton, J. R., 1992: An Introduction to Dynamic Meteorology. 3d ed. Academic Press, 511 pp.

Johnson, R. H., T. M. Rickenbach, S. A. Rutledge, P. E. Ciesielski, and W. H. Schubert, 1999: Trimodal characteristics of tropical convection. J. Climate, 12, 2397-2418.

King, M. D., S.-C. Tsay, S. Platnick, M. Wang, and K.-N. Liou, 1997: Cloud retrieval algorithms for MODIS: Optical thickness, effective particle radius, and thermodynamic phase. MODIS Algorithm Theoretical Basis Doc. ATBD-MOD-05, MOD06-Cloud product, $83 \mathrm{pp}$.

Korolev, A. V., G. A. Isaac, I. P. Mazin, and H. W. Barker, 2001: Microphysical properties of continental clouds from in situ measurements. Quart. J. Roy. Meteor. Soc., 127, 2117-2151.

Kursinski, E. R., G. A. Hajj, K. R. Hardy, J. T. Schofield, and R. Linfield, 1997: Observing Earth's atmosphere with radio occultation measurements using the Global Positioning System. J. Geophys. Res., 102, 23 429-23 465.

Liou, K.-N., 1992: Radiation and Cloud Processes in the Atmosphere: Theory, Observation, and Modeling. Oxford University Press, $487 \mathrm{pp}$.

Liu, C., and M. W. Moncrieff, 1998: A numerical study of the diurnal cycle of tropical oceanic convection. J. Atmos. Sci., 55, 2329-2344.

Livesey, N. J., and Coauthors, 2005: Version 1.5 level 2 data quality and description document. Jet Propulsion Laboratory Tech. Rep. JPL D-32381, 117 pp.

Malkus, J. S., and H. Riehl, 1964: Cloud Structure and Disturbances over the Tropical Pacific Ocean. University of California Press, $229 \mathrm{pp}$.

McClatchey, R. A., W. S. Fenn, J. E. A. Selby, F. E. Volz, and J. S. Garing, 1971: Optical properties of the atmosphere. Air Force Cambridge Research Laboratory Rep. AFCrl-71-0279, $85 \mathrm{pp}$.

McFarquhar, G. M., A. J. Heymsfield, J. Spinhirne, and B. Hart, 2000: Thin and subvisual tropopause tropical cirrus: Observations and radiative impacts. J. Atmos. Sci., 57, 1841-1853.

Platnick, S., M. D. King, S. A. Ackerman, W. P. Menzel, B. A. Baum, J. C. Riedi, and R. A. Frey, 2003: The MODIS cloud products: Algorithms and examples from Terra. IEEE Trans. Geosci. Remote Sens., 41, 459-473.

Reed, R. J., and E. E. Recker, 1971: Structure and properties of synoptic-scale wave disturbances in the equatorial western Pacific. J. Atmos. Sci., 28, 1117-1133.

Remote Sensing Systems, 2006: Updates to the AMSR-E V05 algorithm. Tech. Rep. 020706, 5 pp. [Available online at http://www.remss.com/amsr/amsr_data_description. html\#version.]

Reynolds, R. W., N. A. Rayner, T. M. Smith, D. C. Stokes, and W. Wang, 2002: An improved in situ and satellite SST analysis for climate. J. Climate, 15, 1609-1625.

Riehl, H., and J. S. Malkus, 1958: On the heat balance in the equatorial trough zone. Geophysica, 6, 503-538. 
— trough zone, revisited. Contrib. Atmos. Phys., 52, 287-304.

Sarachik, E. S., 1978: Tropical sea surface temperature: An interactive one-dimensional atmosphere-ocean model. Dyn. Atmos. Oceans, 2, 455-469.

Sassi, F., M. Salby, and W. G. Read, 2001: Relationship between upper tropospheric humidity and deep convection. J. Geophys. Res., 106, 17 133-17 146.

Schmidt, T., J. Wickert, G. Beyerle, and C. Reigber, 2004: Tropical tropopause parameters derived from GPS radio occulta- tion measurements with CHAMP. J. Geophys. Res., 109, D13105, doi:10.1029/2004JD004566.

Schumacher, C., and R. A. Houze, 2003: Stratiform rain in the Tropics as seen by the TRMM precipitation radar. J. Climate, 16, 1739-1756.

Udelhofen, P. M., and D. L. Hartmann, 1995: Influence of tropical cloud systems on the relative humidity in the upper troposphere. J. Geophys. Res., 100 (D4), 7423-7440.

Yanai, M., S. Esbensen, and J.-H. Chu, 1973: Determination of bulk properties of tropical cloud clusters from large-scale heat and moisture budgets. J. Atmos. Sci., 30, 611-627. 


\section{CORRIGENDUM}

Due to an oversight, incorrect versions of Figs. 12 and 13 were published in "Radiative and Convective Driving of Tropical High Clouds," by Terence L. Kubar, Dennis L. Hartmann, and Robert Wood, which was published in the Journal of Climate, Vol. 20, No. 22, 5510-5526. The correct figures are reproduced below in their entirety, as they were intended to be published.

The staff of the Journal of Climate regrets any inconvenience this error may have caused.

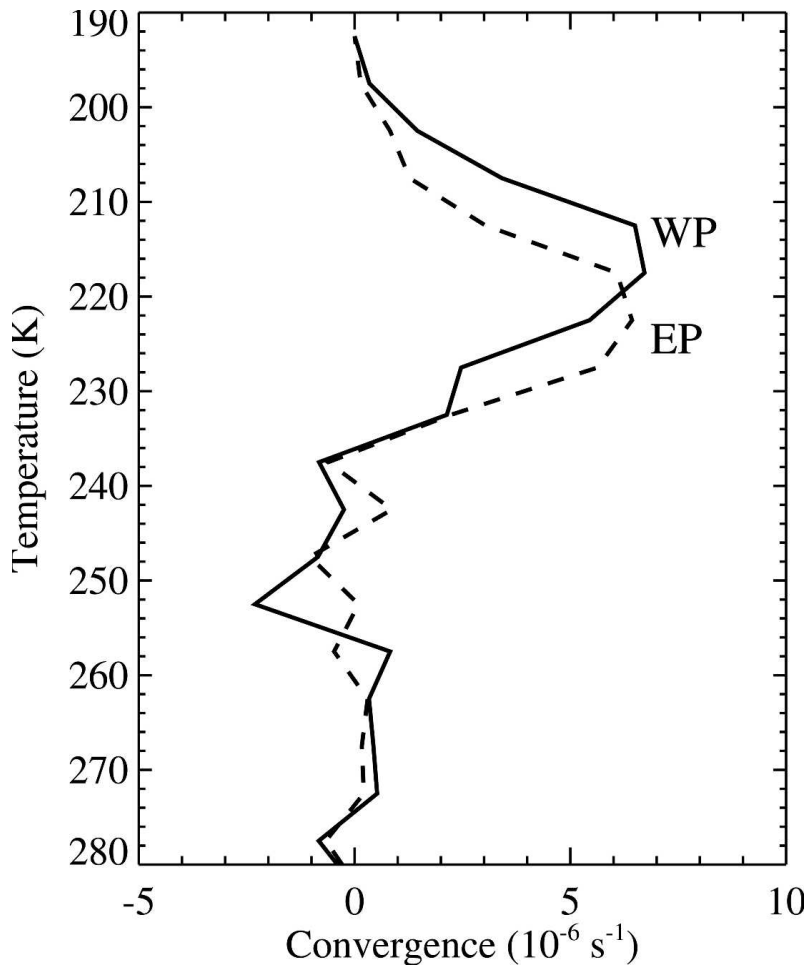

FIG. 12. Binned clear-sky convergence profiles for WP and EP for September 2004-July 2005.

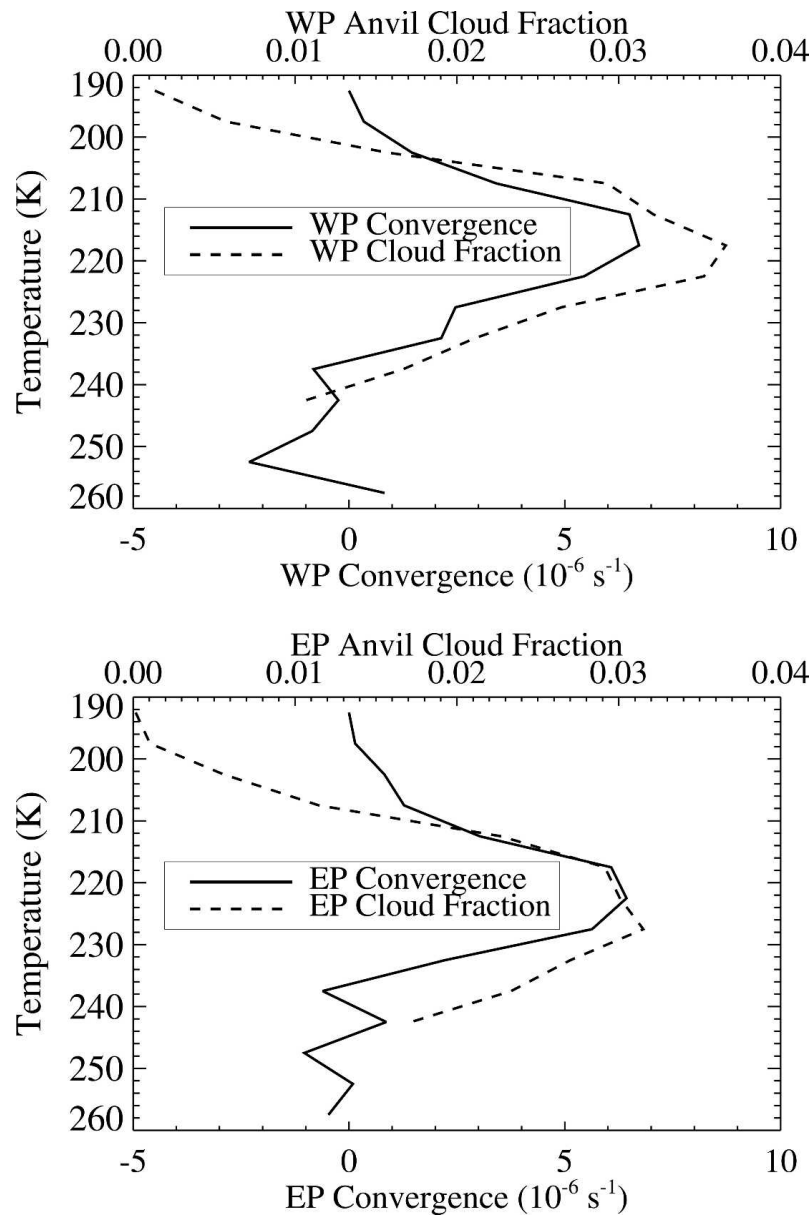

FIG. 13. Clear-sky convergence and anvil cloud fraction for (top) WP and (bottom) EP for September 2004-July 2005. 